Submitted to Materials Science and Engineering A in September 2016, Revised in March 2017

\title{
Hierarchical Evolution and Thermal Stability of Microstructure with Deformation Twins in 316 Stainless Steel
}

\author{
S. J. Wang ${ }^{a \dagger}$, T. Jozaghi ${ }^{\mathrm{b} \dagger}$, I. Karaman ${ }^{\mathrm{a}, \mathrm{b},{ }^{*}, \text { R. } \text { Arroyave }^{\mathrm{a}, \mathrm{b}} \text {, Y.I. Chumlyakov }}{ }^{\mathrm{c}}$ \\ ${ }^{a}$ Department of Materials Science and Engineering, Texas A\&M University, College Station, TX 77843, USA \\ ${ }^{\mathrm{b}}$ Department of Mechanical Engineering, Texas A\&M University, College Station, TX 77843, USA \\ ${ }^{\mathrm{c}}$ Siberian Physical Technical Institute, Tomsk State University, Tomsk 634050, Russia \\ $\dagger$ These authors contributed equally. \\ * Corresponding author: ikaraman@tamu.edu
}

\begin{abstract}
We report extensive nano-twin formation in 316 stainless steel (SS) and the evolution of a hierarchical microstructure through the formation of multi-scale twin bundles after uniaxial tension with uniform elongation levels of $20 \%, 30 \%$, and $40 \%$. Multiscale characterization techniques were employed to reveal the nature of these twins. The twin density increases with the increasing strain level, however, the twin width remains the same, notably reducing the mean free path of dislocations. Concurrently, significant work hardening is observed during subsequent deformation. The deformation-induced nano-twins are thermally stable up to $\sim 800$ ${ }^{\circ} \mathrm{C}$, shown by both interrupted and in-situ transmission electron microscopy experiments, above which the recrystallization takes place in the vicinity of the twins. Such favorable thermal stability of the twins in nano-twin strengthened 316 SS offers a promising approach for microstructurally engineering these materials for potential applications at elevated temperatures. The related strengthening mechanisms are discussed in the light of the mean free path of dislocations and the dislocation interactions with twin boundaries.
\end{abstract}

Keywords: Deformation twinning; 316 stainless steel; Thermal stability; Recrystallization; Strengthening.

\section{Introduction}

In order to improve efficiency of current power plants and decrease their $\mathrm{CO}_{2}$ emission, new structural materials are needed that can perform reliably at higher temperatures. These materials need to maintain their mechanical properties at high temperatures [1, 2]. Aside from the 
expensive Ni-based superalloys, ferritic steels can be utilized for these applications, due to their low thermal expansion coefficient, high thermal conductivity, and irradiation resistance [3], especially in irradiation environments such as nuclear power plants. In fossil fuel power plants, austenitic stainless steels are the materials of choice based on their good high-temperature mechanical properties and oxidation resistance [4]. Further improvements of creep resistance in austenitic stainless steels have been achieved by adding carbide and carbonitride forming alloying elements $[5,6]$, which can pin the grain boundaries as well as mobile dislocations by forming nano-scale particles.

Another method to improve the mechanical properties of austenitic stainless steels is microstructural engineering through thermo-mechanical processing. Dislocation slip and twinning are two competing deformation mechanisms during plastic deformation in austenitic stainless steels. However, the govering deformation mechanism is dictated by both the intrinsic properties of the steels such as crystal orientation or crystallographic texture, grain size, and stacking fault energy (SFE), and the extrinsic conditions such as strain level, strain rate and temperature [7-9]. As an intrinsic property of materials, SFE is the main factor controlling the ease of cross-slip or twinning in face-centered-cubic (fcc) metals and it plays a key role in dictating deformation stages of austenitic stainless steels [10-12]. As the SFE decreases, the separation distance of partial dislocations widens. Thus, cross-slip of dislocations becomes more difficult and mechanical twinning is favored. In austenitic stainless steels (SSs), which commonly have a low to moderate SFE, early stages of deformation are dominated by slip, then stacking faults are formed before twinning dominates the deformation [13]. Formation of twins can provide many interfacial barriers for dislocation motion, reduce the dislocation mean free path which can result in large work hardening coefficients and enhanced tensile strength [9, 14].

Extensive mechanical twinning was observed in $316 \mathrm{~L}$ austenitic SS under various deformation strain paths such as tension [11, 14, 15], compression [11], and severe plastic deformation (SPD) [15-17] due to its intermediate SFE. Although deformation twinning behavior during mechanical deformation has been widely studied in 316 [14] and other types of austenitic stainless steels $[11,14,16,18-20]$, the quantitative information on twins, such as the evolution of the volume fraction and size, under different strain levels, was rarely studied previously [18]. In the present work, we show a hierarchical microstructure evolution in 316 SS due to deformation 
nano-twins and their bundles, and statistically estimate the volume fraction evolution of these twins at different tension strain levels.

Although the formation of deformation twins can significantly enhance the strength, ductility and work-hardening ability are usually sacrificed. Two strategies were recently proposed to achieve a better combination of yield strength and ductility in twinning induced plasticity steels (TWIP), which are based on the thermal stability of mechanically induced twins. One strategy includes the use of partial recrystallization of prestrained materials, either through a cold rolling or dynamic plastic deformation. With this method, TWIP steels with nano-scale mechanical twins were achieved [16, 21-23]. Another strategy is based on the recovery of cold-rolled TWIP steels with nano scale mechanical twins [18-20]. Nano scale twins formed during pre-straining process can significantly increase the strength of the materials [24]. It is expected that a subsequent recovery or partial recrystallization heat treatment should increase ductility and work hardening by reducing the dislocation density between the twins. Bouaziz et al. [20] compared the effect of both recovery and recrystallization on the combination of yield stress and uniform elongation for a given TWIP steel composition at room temperature. They showed that the recovery process allows achieving higher strength-ductility combination than that reached via partial recrystallization. It is then suggested that recovery is a more adequate process, able to increase the initial strength values of TWIP steels, while keeping large ductility levels. The recovery strategy presented on TWIP steels has also been successfully applied to 316L SS leading to a noteworthy combination of high yield strength and strain hardening [25]. However, only one deformation-annealing cycle was performed on that $316 \mathrm{~L}$ SS study. In the present work, the role of several deformation-annealing-deformation cycles on the resulting mechanical response of $316 \mathrm{SS}$ were revealed with the propose of achieving high density of nano scale twins while eliminating dislocations, such that an excellent combination of strength and ductility can be reached.

Clearly, thermally stable mechanical twins can play an important role in the enhancement of strength and ductility combination. However, the investigations on the level of thermal stability of mechanical twins are limited. In conventional Fe-Mn-C steels, mechanical twins were shown to be stable up to $550{ }^{\circ} \mathrm{C}$ for 1 hour heat treatments [26]. Bouaziz et al. observed that the nanometer-scale mechanical twins introduced by pre-straining high-manganese TWIP steels at room temperature were stable up to the recrystallization temperature $\left(625^{\circ} \mathrm{C}\right)$ [19]. They also 
reported that the deformation twins in $316 \mathrm{~L}$ SS after cold rolling to $37 \%$ reduction were stable after a recovery treatment at $600{ }^{\circ} \mathrm{C}$ for one hour [25]. Growth nano twins in as-deposited $330 \mathrm{SS}$ films can survive at $500{ }^{\circ} \mathrm{C}$ for $1 \mathrm{~h}$ [27]. Furthermore, it was shown that the twinning stability can be notably enhanced by microalloying at high temperatures in Fe-Mn austenitic steels with low carbon contents [28]. However, the extent of the thermal stability and the role of these stable twins on the subsequent mechanical response have not been systematically studied. In the present work, various heat treatments are performed on uniaxial tensile deformed $316 \mathrm{SS}$ with different volume fractions of nano-twins. The thermal stability of deformation nano-twins and their effect on the subsequent room temperature mechanical response are studied. The results presented herein can be helpful to exploit new austenitic stainless steels with enhanced performance at elevated temperatures.

\section{Experimental Techniques}

The material in this study is a commercial 316 austenitic SS. The as-received (AR) materials have been forged and solution heat treated at $1000^{\circ} \mathrm{C}$ for $1 \mathrm{~h}$ followed by water-quenching. Dogbone shaped tensile specimens were cut from the AR billets with the gage dimensions of $8 \mathrm{~mm} \times 3 \mathrm{~mm} \times 1 \mathrm{~mm}$ using wire electro-discharge machining (EDM). Uniaxial tensile tests were performed to different strain levels on an MTS servo-hydraulic mechanical test frame, with a strain rate of $10^{-3} \mathrm{~s}^{-1}$ at ambient temperature. The as-deformed samples were annealed at various temperatures from $500{ }^{\circ} \mathrm{C}$ to $1200{ }^{\circ} \mathrm{C}$ for an isochronal time, $1 \mathrm{~h}$. Each sample was sealed in quartz tubes with argon environment to avoid oxidation during the heat treatment (HT) process. The Vickers hardness was measured by an LM 300AT microhardness tester using $0.3 \mathrm{~kg}$ force $(2.9 \mathrm{~N})$ at a loading time of $13 \mathrm{~s}$. Each hardness value reported was averaged from at least 20 indents. In addition, a set of cyclic tension tests were conducted to investigate the role of several deformation-annealing-deformation cycles on the resulting mechanical response of 316 SS, which consisted of: two cycles of tension tests to an engineering strain of $30 \%$ followed by heat treatment at $800^{\circ} \mathrm{C}$ for 1 hour then water quenching, completed by a final tension test until failure.

The microstructure examinations were performed by optical microscopy (OM), scanning electron microscopy (SEM), and transmission electron microscopy (TEM). The OM images were captured with a Keyence digital VH-Z100 optical microscope. SEM experiments were conducted 
using a field emission FEI Quanta 600 microscope. The samples for OM and SEM studies were mechanically polished following the standard metallographic sample preparation procedures and then etched using a solution of $10 \mathrm{ml}$ nitric acid, $30 \mathrm{ml}$ hydrochloric acid and $30 \mathrm{ml}$ distilled water for 2 3 minutes. TEM characterizations were performed using FEI Tecnai $G^{2}$ F20 microscope operated at $200 \mathrm{kV}$. In situ heating experiments were conducted on a Gatan singletilt heating holder (Model 628-0500) within a JEOL 2010 microscope. The disc specimens for TEM observation were mechanically thinned to $50 \mu \mathrm{m}$, and then were prepared by using a double-jet electrolytic polishing in a mixture of $10 \%$ perchloric acid and $90 \%$ ethanol at $20 \mathrm{~V}$ and $\sim-20^{\circ} \mathrm{C}$.

\section{Results}

\subsection{Microstructural evolution during tensile deformation, and static and in-situ annealing}

Representative microstructures of the as-received materials are shown in Fig. 1, obtained using OM (Fig.1a) and TEM (Fig.1b). Equiaxed grains with an average size around $60 \mu \mathrm{m}$ were detected using the linear intercept method. Annealing twins are noted in some grains in the figure. There are few dislocations within grains as shown in Fig.1b. The Vickers hardness of the AR specimens was measured to be $151.5 \pm 4.6$.

Tensile tests until failure were performed on the as-received (AR) samples (Fig. 2). The true uniform elongation was determined to be $\sim 47 \% \pm 1 \%$. Significant work hardening was noticed in the AR samples. Engineering strains of $10 \%, 20 \%, 30 \%$ and $40 \%$ were chosen to study the evolution of the microstructure in the AR specimens during deformation.

After $10 \%$ deformation, most of the grains have numerous planar dislocation structures shown in Fig. 3a with a TEM image. In the $20 \%, 30 \%$ and $40 \%$ deformed specimens, many nanoscale deformation bands coupled with high density of dislocations were detected as shown in Figs. 3(b-d). These bands were verified as deformation twins using selected area diffraction patterns (SADP) in the inserted image in Fig. 3b which shows these twins to be $\{111\}<112>$ type. After $800^{\circ} \mathrm{C}$ heat treatments (HTs) for 1 hour, most of the dislocations in the deformed specimens were recovered, but the nano-twin bands were preserved, as shown in Fig. 4. After $900^{\circ} \mathrm{C}$ HTs for 1 hour, some deformation nano-twins still existed, and recrystallization appeared in all the deformed specimens. Microstructure differences were noticed between $(20 \%, 30 \%)$ $900^{\circ} \mathrm{C}$ HT and $40 \%-900{ }^{\circ} \mathrm{C}$ HT samples. The major microstructural features in the $(20 \%, 30 \%)$ - 
$900{ }^{\circ} \mathrm{C}$ HT samples are deformation nano-twins as shown in Figs. 5(a,b), and the minor microstructural features are recrystallized grains as shown in Figs. 5(d,e). However, in the 40\%$900{ }^{\circ} \mathrm{C}$ HT samples, the major microstructural features are recrystallized grains (Fig. 5c), and deformation twins still exist in few grains (Fig. 5f). These recrystallized grains are generally several microns in size. Interestingly, some recrystallized grains were captured forming at the intersection of two different twin variants (Fig. 6).

In situ TEM heating experiments were performed to study the microstructure evolution in situ, in particular the thermal stability of deformation nano-twins in tension samples. Fig. 7a reveals that there are nano-twin bands and high density of dislocations in the $20 \%$ deformed samples at room temperature. The inserted SADP shows these twins are $\{111\}<112>$ type. Fig. $7 \mathrm{~b}$ shows the dark field image of these nano twin bands. As the temperature increased, the dislocations disappeared gradually, but nano-twins were stable up to $900^{\circ} \mathrm{C}$ (Fig. $7 \mathrm{c}$ ). At $1000^{\circ} \mathrm{C}$, disintegration of the thin foil started at the thinnest area near the hole of the TEM samples, but the nano-twin bands still remained stable (Fig. 7d). At first, it was not possible to find an obvious structure to assess what happens to nano-twin bands at this temperature and whether the detwinning occurs in the twin bands of Fig. $7 \mathrm{~d}$. After annealing at $1000^{\circ} \mathrm{C}$ for about 30 minutes, a characteristic microstructure appeared, labeled by white arrows in Figs. 7(e, f), which is used as a location mark. Comparing the position of this mark and the twin band in Fig. 7e, the nanotwin band was verified to disappear gradually starting from the lower end of the sample. Nanotwin bands completely disappeared after $\sim 37$ minutes at $1000^{\circ} \mathrm{C}$ as shown in Fig. $7 \mathrm{f}$. To the best of the author's knowledge this is the first in-situ study that demonstrates how nano-twins disappear during annealing of stainless steels and clearly proves the occurrence of detwinning.

\subsection{Evolution of mechanical properties}

Heat treatments (HTs) at temperatures from $500^{\circ} \mathrm{C}$ to $1200^{\circ} \mathrm{C}$ were performed for 1 hour on the $20 \%, 30 \%$ and $40 \%$ strained tension samples of $316 \mathrm{SS}$, followed by water quenching. The corresponding hardness evolution at room temperature after HTs is shown in Fig. 8a. Hardness remained unchanged or slightly increased after HTs up to $600^{\circ} \mathrm{C}$ annealing and dropped slightly from $600^{\circ} \mathrm{C}$ to $800^{\circ} \mathrm{C}$. After annealing above $800^{\circ} \mathrm{C}$, a significant softening occurred. At $1000^{\circ} \mathrm{C}$, the deformed materials were fully recrystallized and the hardness was comparable to the hardness of the as-received materials. 
Fig. 9 provides a comparison of the tensile true stress-strain responses between as-received specimen and as annealed samples $\left(800 / 900{ }^{\circ} \mathrm{C}\right.$ HT for 1 hour on the $20 \%, 30 \%$ and $40 \%$ prestrained samples). The tensile curves of the $30 \%-800^{\circ} \mathrm{C}$ HT and $40 \%-800^{\circ} \mathrm{C}$ HT samples show a significant increase in tensile yield strength (from $\sim 254 \mathrm{MPa}$ to $\sim 570 \mathrm{MPa}$, also see Fig. $8 \mathrm{~b}$ ) and retention of considerable ductility (about $\sim 35 \%$ ) as compared to the AR specimens. $900^{\circ} \mathrm{C} \mathrm{HT}$ of the $20 \%, 30 \%$ and $40 \%$ pre-strained samples and $800^{\circ} \mathrm{C}$ HT on the $20 \%$ deformed samples present less strengthening, but again a retained ductility. The yield strengths of the specimens after heat treatments are summarized in Fig. $8 \mathrm{~b}$ and compared with the ultimate tensile strengths of the $20 \%, 30 \%$ and $40 \%$ deformed samples such that it is possible to see the level of reduction in strength after the annealing heat treatments. The yield strength of the AR specimen is also included for comparison. After $800^{\circ} \mathrm{C} \mathrm{HT}$, dislocations are mostly recovered so the hardness and strength decrease slightly. After $900^{\circ} \mathrm{C} \mathrm{HT}$, the hardness and strength of the $30 \%$ and $40 \%$ deformed specimens dropped considerably as compared to that of the $20 \%$ deformed specimens. However, all the hardness and strength levels of the deformed and annealed samples (after 800 and $900^{\circ} \mathrm{C} \mathrm{HTs}$ ) are still higher than those of the as-received sample.

From the above results, it can be seen that the deformation and annealing cycles can enhance the strength and ductility property combination in 316 SS samples due to the thermal stability of deformation nano-twins. To illustrate this better and quantity the amount of improvement, 30\% tensile strain was applied to an as-received sample (red tension curve in Fig. 10a). A post deformation annealing process was carried out at $800^{\circ} \mathrm{C}$. The annealed sample was then deformed an additional 30\% tensile strain (see the blue tension curve in Fig. 10a), unloaded, and annealed again at $800^{\circ} \mathrm{C}$. After this second annealing, the specimen is pulled to failure (dark green tension curve in Fig. 10a). Comparing the three tension tests, the yield strength is significantly increased from $\sim 254 \mathrm{MPa}$ to $\sim 525 \mathrm{MPa}$ (secondary tension) to $635 \mathrm{MPa}$ (third tension). The 2 nd and 3 rd tension curves were shifted in order to clearly show the strengthening effect of the anneal-tension cycles on the samples as compared to the as-received sample. The ultimate tensile strength before fracture of the sample after anneal-tension cycles is $\sim 1096 \mathrm{MPa}$ which is higher than the ultimate tensile strength of the as-received sample ( 978 MPa).

\section{Discussion of the Results:}

\subsection{Hierarchical microstructure evolution under different strain levels}


Microstructural evolution in the samples after 20\%, 30\% and 40\% tensile strains are shown in Fig. 11. Numerous parallel bands were formed in most grains at each strain level. These bands were shown to be $\{111\}<112>$ twin bands via the TEM investigations. Before mechanical twinning was activated, the dislocation slip was the dominant deformation mechanism, and a high density of planar dislocations was generated under 10\% strain deformation as shown in Fig. 3a. The formation of planar dislocations can reduce the ability of a material to cross-slip and cause the early onset of twinning. Figs. 11( $\mathrm{a}_{1}, \mathrm{~b}_{1}$ and $\left.\mathrm{c}_{1}\right)$ show the low magnification SEM images of the microstructures after $20 \%, 30 \%$ and $40 \%$ strains, respectively. It is obvious that at $20 \%$ elongation, straight deformation twins are already present in more than $\sim 50 \%$ of the grains (Fig. 11 $\mathrm{a}_{1}$ ). Generally, only one twinning system was activated in most of the twinned grains which is also evidenced by the TEM image (Fig. 3b), but their volume fraction in each grain is relatively low. The number density of the twinned grains is estimated as $62.6 \% \pm 4.6 \%$ of total grains, determined by counting about 500 grains. The density of twins in every twinned grain is depicted for the $20 \%$ deformed samples in Fig. 12 , the average value is $\sim 6.6 \% \pm 4.7 \%$, calculated using $\sim 70$ grains. At a higher strain level, i.e. $30 \%$ or $40 \%$, in most of the grains, a second twinning system was activated. There are more interactions between these two twinning systems in the $40 \%$ deformed specimens as compared to the $30 \%$ deformed specimens as can be seen in Fig. 11. The twinned-grain number fractions of the $30 \%$ and $40 \%$ deformed samples are determined as $77.3 \% \pm 3.1 \%$ and $79.5 \% \pm 4.3 \%$, respectively, from about 500 grains, which are close to each other but larger than that of $20 \%$ strain sample. However, the twin densities in single twinned grains present a large difference between $30 \%$ and $40 \%$ deformed samples, as shown in the histograms of Fig. 12. The twin density increases from $\sim 11.0 \% \pm 7.3 \%$ to $16.2 \% \pm$ $6.8 \%$ with increasing strain level from $30 \%$ to $40 \%$. This reveals that the twinning activity is enhanced as the tensile strain increases from $10 \%$ to $40 \%$. The measured twin densities are also summarized in Table 1. The twin density in the entire sample is also measured using a total of about 500 grains. The total twin densities in each of the $20 \%, 30 \%$ and $40 \%$ deformed samples are determined to be $5.8 \% \pm 1.5 \%, 9.4 \% \pm 1.6 \%$ and $12.5 \% \pm 2.0 \%$. In the $30 \%$ deformed sample after the deformation-annealing-deformation cycles, the twinning is activated in almost every grain after the third tensile loading (Fig. 10). The final twin density reaches to $\sim 28.4 \% \pm$ $4.5 \%$ which is much higher than $12.5 \% \pm 2.0 \%$ of the $40 \%$ deformed sample. This shows that the deformation-annealing-deformation cycles can efficiently increase the twin density in 316 SS. 
In Figs. $11\left(a_{2}, b_{2}\right.$ and $\left.c_{2}\right)$, a single grain is selected to show the twin morphology at each strain level. It is obvious that within a single grain, the twin band density increases with increasing strain. The maximum twin density in an individual grain was estimated to be around $33 \%$ for both $30 \%$ and $40 \%$ strain, which indicates the approximate upper limit of deformation twin density achieved via uniaxial tensile deformation at room temperature. Figs. $11\left(\mathrm{a}_{3}, \mathrm{~b}_{3}\right.$ and $c_{3}$ ) present the submicron scale details of twin bands and their interactions at each strain level. The TEM images shown in Figs. 11( $a_{4}, b_{4}$ and $\left.c_{4}\right)$ indicate that the bands seen at submicron scale in SEM images are actually bundles of nano-twins, which are similar to nano-twin bundles shown earlier in 316L austenitic stainless steel after dynamic plastic deformation [16]. These nano scale twin bundles with a high density of parallel twin boundaries are difficult to be traversed by another twin band or bundle. Therefore, there are many bands or twin bundles stopped at one side of another twin bundle. Thin twins and twin bundles are common features of low SFE austenitic steels, and these microstructures significantly contribute to work hardening $[15,17,29,30]$. Figs. $11\left(d_{1}-d_{4}\right)$ are the schematic representations of the hierarchical morphology of the deformation twins 316 SS. These schematics clearly show the details of twin bands or bundles and their interactions after uniaxial tensile deformation.

Furthermore, with the help of dark field (DF) images of twin bands, the twin width is statistically measured as summarized in Fig. 13. The average twin widths are on the order of 30$35 \mathrm{~nm}$ for all three samples determined by measuring more than 700 nano twin bands at their edge-on condition in DF TEM images. Compared to the twin density, the changes in twin width at different strain levels are insignificant. A previous study demonstrated that twin thickness is dependent on SFE, strain rate, and deformation temperature [31]. Low SFE, high strain rates, and low temperatures were shown to effectively reduce the critical twin nucleus thickness and resist the propagation of twins, resulting in finer deformation twins. Under a strain as high as 116\% during equal channel angular extrusion of 316L SS [15], the average twin thickness was about 35 $\mathrm{nm}$ which is comparable to that in the present work. This reveals that twin thickness is independent of the extent of deformation.

It is well known that martensitic transformation can be induced under plastic deformation at low temperatures in many austenitic stainless steels [32-35]. Seetharaman and Krishnan [36] reported, in $316 \mathrm{SS}$, a considerable amount of martensite (around 30\% vol.\%) formed under $\sim 30 \%$ true strain uniaxial tension and rolling at $-196{ }^{\circ} \mathrm{C}$. However, after the deformation at 25 
${ }^{\circ} \mathrm{C}$, very little martensite was noticed even at very large strains. In the current work, martensite phase was absent in the uniaxial tension deformed samples verified using TEM and XRD.

\subsection{Thermal stability of deformation nano-twins}

The thermal stability of deformation twins at elevated temperatures is not well-known, compared with the nucleation and growth mechanisms of deformation twins. Nano scale deformation twins and twin bundles were reported to form during equal channel angular extrusion in $316 \mathrm{~L} \mathrm{SS}$ at temperatures as high as $800^{\circ} \mathrm{C}(0.6 \mathrm{Tm}, \mathrm{Tm}$ is the melting temperature in K) [15]. The nano-twins in $\mathrm{Cu}$ and $330 \mathrm{SS}$ films were shown to exhibit notable thermal stability. Nano twins remained stable at $800^{\circ} \mathrm{C}\left(0.79 \mathrm{~T}_{\mathrm{m}}\right)$ in $\mathrm{Cu}$ and $500^{\circ} \mathrm{C}$ in $330 \mathrm{SS}$ films, respectively [27]. In the present study, it's revealed that the nano twins in deformed $316 \mathrm{SS}$ materials can be stable up to $800^{\circ} \mathrm{C}\left(0.6 \mathrm{~T}_{\mathrm{m}}\right)$, and no detectable coarsening of the nano twins was observed in TEM investigations under edge-on conditions for the twin boundaries. At $800^{\circ} \mathrm{C}$ heat treatment for 1 hour, recrystallization was not observed in any of the $20 \%, 30 \%$ and $40 \%$ deformed samples, but the dislocation density obviously decreased compared with the corresponding asdeformed samples. Due to the higher density of twin bands under higher strain, the yield strength of the post annealed $40 \%$ deformed samples is higher than that of the post annealed $20 \%$ and $30 \%$ deformed samples (shown in Fig. 8b). However, recrystallization starts at $900^{\circ} \mathrm{C}$ heat treatment for 1 hour (shown in Fig. 5). Even though primary recrystallization was locally initiated at $900^{\circ} \mathrm{C}$ heat treatment, the deformation twins were maintained in the microstructure unless they were consumed by the growth of the recrystallized grains into the deformed matrix, as illustrated in Fig. 6. The deformation twins were found to be thermally stable in the nonrecrystallization zone even at $900^{\circ} \mathrm{C}$ heat treatment (see Figs. 5f, 6 and 7c).

In addition, based on the in-situ TEM heating experiments, the nano twins are clearly stable at $900^{\circ} \mathrm{C}$, as no coarsening and detwinning were discerned. The temperature of the heating stage (Model 628-0500) used in these experiments was determined to be accurate to within a few degrees. However, there is greater uncertainty about the actual temperature at the observation location because the thermocouple mounted on the heating stage is not directly contact with specimen. The temperature obtained by the thermocouple is the furnace temperature and should be considered as the maximum as there was no method for independently determining the actual specimen temperature at the position of observation. Based on the previous investigations in the 
literature, a $50{ }^{\circ} \mathrm{C}$ difference between measured temperature of the holder and actual specimen temperature can be expected [37,38]. Thus, through the in-situ experiments, it can be confidently stated that deformation nano-twins have remarkable thermal stability at least up to $800^{\circ} \mathrm{C}(0.6 \mathrm{Tm})$ in $316 \mathrm{SS}$ which is consistent with the ex-situ experiments.

\subsection{Effect of thermally stable deformation twins on post-annealing mechanical response}

Following Kocks et al. [39, 40], the dynamic evolution of dislocation density can be written as:

$$
\frac{d \rho}{d \varepsilon}=\left(\frac{d \rho}{d \varepsilon}\right)_{+}-\left(\frac{d \rho}{d \varepsilon}\right)_{-}=\frac{1}{b \lambda}-k \rho
$$

where $\rho$ is the dislocation density, $\varepsilon$ is the strain, $b$ is burgers vector, $\lambda$ is dislocation mean free path, and $\mathrm{k}$ is the recovery coefficient. The term $\frac{d \rho}{d \varepsilon}$ is the net dislocation storage rate. The first term $\left(\frac{d \rho}{d \varepsilon}\right)_{+}$is related to dislocation storage and $\left(\frac{d \rho}{d \varepsilon}\right)_{-}$is the dislocation dynamic recovery term. The increase of dislocation density arises from the accumulation of immobile dislocations which are actually the dislocations arrested by strong obstacles. In other words, any obstacles blocking dislocation motion will result in strain hardening. These obstacles could be forest dislocations, grain boundaries, twin boundaries, or precipitation particles. Thus, the dislocation mean free path $\lambda$ can reflect the strengthening mechanism. A small $\lambda$ value reflects a quick accumulation of immobile dislocation.

Applying the rule of mixture, the dislocation mean free path can be written as [41]:

$$
\frac{1}{\lambda}=\frac{1}{d}+K \sqrt{\rho}
$$

where $d$ is effective grain size, and $\mathrm{K}$ is a constant. The second term on the right hand side is related to the forest dislocation spacing. When twinning occurs, the effective size of the twinned grain will decrease significantly.

In the present case, the low dislocation density and the large grain size of the as-received material results in a large $\lambda$ value, thus the low yield strength (shown in Fig. 9 black curve). However, dislocation tangles or cells and twinning occur during deformation. Thus the blockage of dislocations by as-formed dislocation tangles and twin boundaries can provide further strengthening of $316 \mathrm{SS}$ and postpone necking, which results in a significant work hardening. 
The onset of necking in the as-received sample is at $\sim 47 \%$ true strain (Fig. 9). The annealing of $20 \%, 30 \%$ and $40 \%$ deformed specimens reduces the dislocation density, but the twin boundaries survive (due to their thermal stability). Thus the yield strengths of the annealed samples are higher, compared to the as-received case. The hardening behavior of the as-received and $40 \%$ $800^{\circ} \mathrm{C}$ and $40 \%-900^{\circ} \mathrm{C}$ are given in Fig. 14. The strain hardening rate of $40 \%-800^{\circ} \mathrm{C}$ and $40 \%$ $900^{\circ} \mathrm{C}$ samples are clearly higher at a given stress level than the as-received sample due to the higher density of twin boundaries and the positive influence of twin boundaries in reducing the mean free path of dislocations.

Strain hardening rate vs. applied strain response for the as-received material reveals different hardening stages and corresponding microstructure evolution during uniaxial tensile tests. At the initial stages of plastic deformation, the strain hardening is very high and steadily decreases when strain is below $\sim 17 \%$ (Fig. 14 black square line). The microstructure within this stage reveals a planar arrangement of dislocations (evidenced by microstructure of $10 \%$ deformation sample as shown in Fig. 3a) which was noted in previous studies of low SFE materials [29]. With increasing strain, the hardening curve exhibits an almost constant strain hardening rate which is due to twinning. At the onset of this stage, mechanical twinning is activated. Twins can serve as obstacles against dislocation motion. They create a small $\lambda$ value and thus promote strain hardening. Further straining in this stage is found to produce more twins and twin bundles (Fig. 11 $\mathrm{a}_{4}$ ), and twinned-grain fraction rises from $62.6 \% \pm 4.6 \%$ to $77.3 \% \pm$ $3.1 \%$ as true strain increases from $18 \%$ to $26 \%$ (corresponding to engineering strains from $20 \%$ to $30 \%)$. After this stage, a second regime of decreasing strain hardening rate appears again when strain is larger than $\sim 27 \%$. Between true strains of $26 \%$ and $33 \%$ (engineering strain from $30 \%$ to $40 \%$ ), the trend of increase in twinned grain fraction continues but the rate of increase is very low (from $77.3 \% \pm 3.1 \%$ to $79.5 \% \pm 4.3 \%$ ) and twin-twin intersections were observed in this stage. Due to the apparent difficulty of forming more deformation twins with further straining in this stage, the strain hardening rate drops steadily.

Fig. 15 shows the strength and ductility combination in $316 \mathrm{SS}$ after various processing conditions. For comparison, the data from 316L SS processed by Equal channel angular pressing (ECAP) [17] and dynamic plastic deformation (DPD) [16] were included in Fig. 15. Although the strength of 316L SS can be significantly increased by these severe plastic deformation (SPD) methods, the ductility is always sacrificed. The current study illustrates a method which can 
achieve an excellent ductility with moderate strengthening. This could be applied as a complementary method to SPD and DPD.

\section{Summary and Conclusions:}

In the present study, in order to investigate the microstructural evolution of the 316 stainless steel polycrystals, the samples were uniaxially loaded to $10 \%, 20 \%$, and $30 \%$ tensile strains, and the deformed samples were studied in detail using SEM and TEM. Deformation features evolve from planar dislocations to single system twinning, then, to multi systems twinning and intersections among twin bands or bundles, with increase in strain. With further straining, twin density goes up, but twin width remains on the order of $\sim 30 \mathrm{~nm}$ due to the low stacking fault energy and twin fault energy, and high lattice friction against twin dislocation motion. The microstructure has evolved into a hierarchical ensemble of features in different length scales: the nano-scale twins forming low-micron scale bundles within micron-scale grains.

A series of annealing experiments were performed on the deformed specimens to evaluate the thermal stability of the deformation twins. TEM studies on the annealed samples revealed that after $800^{\circ} \mathrm{C}$ annealing for 1 hour, the twin density stayed almost at the same level but the dislocation density obviously decreased as compared to the as-deformed samples. Coarsening of the nano twins and recrystallization were not detected in any deformed samples after this annealing treatment. These nano twins show prominent thermal stability up to $\sim 800^{\circ} \mathrm{C}$ as revealed by both ex-situ and in-situ TEM experiments. Ex-situ heat treatments revealed that at $900^{\circ} \mathrm{C}$ for 1 hour, recrystallization occurs (starting at the intersection of two twin variants) while some nano-twins still remain stable. Furthermore, in-situ heat treatment in TEM showed the nano-twins start to disappear at $1000^{\circ} \mathrm{C}$.

Presence of these thermally-stable nano-twins led to a significant increase in tensile yield strength (from $\sim 254 \mathrm{MPa}$ to $\sim 570 \mathrm{MPa}$ ) and retention of considerable ductility in the deformed plus annealed samples. After annealing treatments, twin density almost stays the same and the dislocation density drops. Since the dislocation mean free path is reduced due to the twin boundaries in both deformed and annealed samples, strain hardening is higher at a given stress level in the annealed samples due to the better dislocation storage capability. Based on this, a further increase in the yield strength was achieved in the samples after deformation-annealingdeformation cycles, through increasing the volume fraction of the twins. The strategy presented 
in the current work provides a possible method to obtain a high strength 316 SS without sacrificing ductility.

\section{Acknowledgements}

This study was supported by the US Department of Energy - National Energy Technology

Laboratory (NETL) under the program "Support of Advanced Coal Research at United States Colleges and Universities," with the grant number of DE-FE0008719.

\section{References}

1. Viswanathan, R. and W. Bakker, Materials for ultrasupercritical coal power plants-Boiler materials: Part 1. Journal of Materials Engineering and Performance, 2001. 10(1): p. 81-95.

2. Viswanathan, R. and W. Bakker, Materials for ultrasupercritical coal power plants-Turbine materials: Part II. Journal of Materials Engineering and Performance, 2001. 10(1): p. 96-101.

3. Klueh, R. and A. Nelson, Ferritic/martensitic steels for next-generation reactors. Journal of Nuclear Materials, 2007. 371(1): p. 37-52.

4. Sourmail, T., Precipitation in creep resistant austenitic stainless steels. Materials science and technology, 2001. 17(1): p. 1-14.

5. Taneike, M., F. Abe, and K. Sawada, Creep-strengthening of steel at high temperatures using nano-sized carbonitride dispersions. Nature, 2003. 424(6946): p. 294-296.

6. Yamamoto, Y., M. P. Brady, Z. P. Lu, P. J. Maziasz, C. T. Liu, B. A. Pint, K. L. More, H. M. Meyer, and E. A. Payzant, Creep-resistant, $\mathrm{Al}_{2} \mathrm{O}_{3}$-forming austenitic stainless steels. Science, 2007. 316(5823): p. 433-436.

7. Karaman, I., H. Sehitoglu, K. Gall, Y.I. Chumlyakov, and H.J. Maier, Deformation of single crystal Hadfield steel by twinning and slip. Acta materialia, 2000. 48(6): p. 1345-1359.

8. Christian, J.W. and S. Mahajan, Deformation twinning. Progress in materials science, 1995. 39(1): p. 1-157.

9. Karaman, I., H. Sehitoglu, A.J. Beaudoin, Y.I. Chumlyakov, H.J. Maier, and C.N. Tomé, Modeling the deformation behavior of Hadfield steel single and polycrystals due to twinning and slip. Acta Materialia, 2000. 48(9): p. 2031-2047.

10. El-Danaf, E., S.R. Kalidindi, and R.D. Doherty, Influence of grain size and stacking-fault energy on deformation twinning in fcc metals. Metallurgical and Materials Transactions A, 1999. 30(5): p. 1223-1233.

11. Karaman, I., H. Sehitoglu, Y. I. Chumlyakov, and H. J. Maier, The deformation of low-stackingfault-energy austenitic steels. JOM, 2002. 54(7): p. 31-37.

12. Vercammen, S., B. Blanpain, B.C. De Cooman, and P. Wollants, Cold rolling behaviour of an austenitic $\mathrm{Fe}-30 \mathrm{Mn}-3 \mathrm{Al}-3 \mathrm{Si}$ TWIP-steel: the importance of deformation twinning. Acta Materialia, 2004. 52(7): p. 2005-2012.

13. Peng, R.L., M. Odén, Y.D. Wang, and S. Johansson, Intergranular strains and plastic deformation of an austenitic stainless steel. Materials Science and Engineering: A, 2002. 334(1): p. 215-222.

14. Karaman, I., H. Sehitoglu, H.J. Maier, and Y.I. Chumlyakov, Competing mechanisms and modeling of deformation in austenitic stainless steel single crystals with and without nitrogen. Acta materialia, 2001. 49(19): p. 3919-3933. 
15. Yapici, G., I. Karaman, Z.P. Luo, H.J. Maier, and Y.I. Chumlyakov, Microstructural refinement and deformation twinning during severe plastic deformation of $316 \mathrm{~L}$ stainless steel at high temperatures. Journal of materials research, 2004. 19(08): p. 2268-2278.

16. Yan, F., G.Z. Liu, N.R. Tao, and K. Lu, Strength and ductility of 316L austenitic stainless steel strengthened by nano-scale twin bundles. Acta Materialia, 2012. 60(3): p. 1059-1071.

17. Ueno, H., et al., Nanostructurization assisted by twinning during equal channel angular pressing of metastable 316L stainless steel. Journal of materials science, 2011. 46(12): p. 4276-4283.

18. Bouaziz, O., et al., High manganese austenitic twinning induced plasticity steels: A review of the microstructure properties relationships. Current Opinion in solid state and materials science, 2011. 15(4): p. 141-168.

19. Bouaziz, O., C. Scott, and G. Petitgand, Nanostructured steel with high work-hardening by the exploitation of the thermal stability of mechanically induced twins. Scripta Materialia, 2009. 60(8): p. 714-716.

20. Bouaziz, O. and D. Barbier, Benefits of Recovery and Partial Recrystallization of Nanots of Recovery and Partial Advanced Engineering Materials, 2013. 15(10): p. 976-979.

21. Wang, H., N. Tao, and K. Lu, Strengthening an austenitic Fe-Mn steel using nanotwinned austenitic grains. Acta Materialia, 2012. 60(9): p. 4027-4040.

22. Kang, S., et al., Effects of recrystallization annealing temperature on carbide precipitation, microstructure, and mechanical properties in Fe-18Mn-0.6 C-1.5 Al TWIP steel. Materials Science and Engineering: A, 2010. 527(3): p. 745-751.

23. Dini, G., et al., Improved tensile properties of partially recrystallized submicron grained TWIP steel. Materials Letters, 2010. 64(1): p. 15-18.

24. Zhao, W., et al., High density nano-scale twins in $\mathrm{Cu}$ induced by dynamic plastic deformation. Scripta materialia, 2005. 53(6): p. 745-749.

25. Bouaziz, O. and D. Barbier, Strain-Hardening in Nano-Structured Single Phase Steels: Mechanisms and Control. Journal of nanoscience and nanotechnology, 2012. 12(11): p. 87328734.

26. Wang, X., et al., Microstructural features controlling the deformation and recrystallization behaviour $\mathrm{Fe}-30 \% \mathrm{Mn}$ and $\mathrm{Fe}-30 \% \mathrm{Mn}-0.5 \% \mathrm{C}$. Materials Science and Engineering: A, 2010. 527(16): p. 3785-3791.

27. Zhang, X. and A. Misra, Superior thermal stability of coherent twin boundaries in nanotwinned metals. Scripta Materialia, 2012. 66(11): p. 860-865.

28. Randle, V. and V. Randle, The role of the coincidence site lattice in grain boundary engineering. 1996: Institute of Materials London.

29. Asgari, S., et al., Strain hardening regimes and microstructural evolution during large strain compression of low stacking fault energy fcc alloys that form deformation twins. Metallurgical and Materials Transactions A, 1997. 28(9): p. 1781-1795.

30. $\mathrm{Wu}, \mathrm{X}$., et al., The role of deformation mechanisms in flow localization of $316 \mathrm{~L}$ stainless steel. Journal of nuclear materials, 2006. 356(1): p. 70-77.

31. Zhang, Y., N. Tao, and K. Lu, Effect of stacking-fault energy on deformation twin thickness in $\mathrm{Cu}$-Al alloys. Scripta Materialia, 2009. 60(4): p. 211-213.

32. Patel, J. and M. Cohen, Criterion for the action of applied stress in the martensitic transformation. Acta Metallurgica, 1953. 1(5): p. 531-538.

33. Kelly, P. and J. Nutting, The morphology of martensite. J. Iron Steel Inst, 1961. 197(3): p. 199211.

34. Üçok, İ., T. Ando, and N.J. Grant, Property enhancement in Type 316L stainless steel by spray forming. Materials Science and Engineering: A, 1991. 133: p. 284-287.

35. Eskandari, M., A. Najafizadeh, and A. Kermanpur, Effect of strain-induced martensite on the formation of nanocrystalline 316L stainless steel after cold rolling and annealing. Materials Science and Engineering: A, 2009. 519(1): p. 46-50. 
36. Seetharaman, V. and R. Krishnan, Influence of the martensitic transformation on the deformation behaviour of an AISI 316 stainless steel at low temperatures. Journal of Materials Science, 1981. 16(2): p. 523-530.

37. Holloway, K. and R. Sinclair, High-resolution and in situ TEM studies of annealing of Ti-Si multilayers. Journal of the Less Common Metals, 1988. 140: p. 139-148.

38. Sinclair, R., M. Parker, and K. Kim, In situ high-resolution electron microscopy reactions in semiconductors. Ultramicroscopy, 1987. 23(3): p. 383-395.

39. Mecking, H. and U. Kocks, Kinetics of flow and strain-hardening. Acta Metallurgica, 1981. 29(11): p. 1865-1875.

40. Kocks, U. and H. Mecking, Physics and phenomenology of strain hardening: the FCC case. Progress in materials science, 2003. 48(3): p. 171-273.

41. Bouaziz, O. and N. Guelton, Modelling of TWIP effect on work-hardening. Materials Science and Engineering: A, 2001. 319: p. 246-249. 


\section{FIGURES}
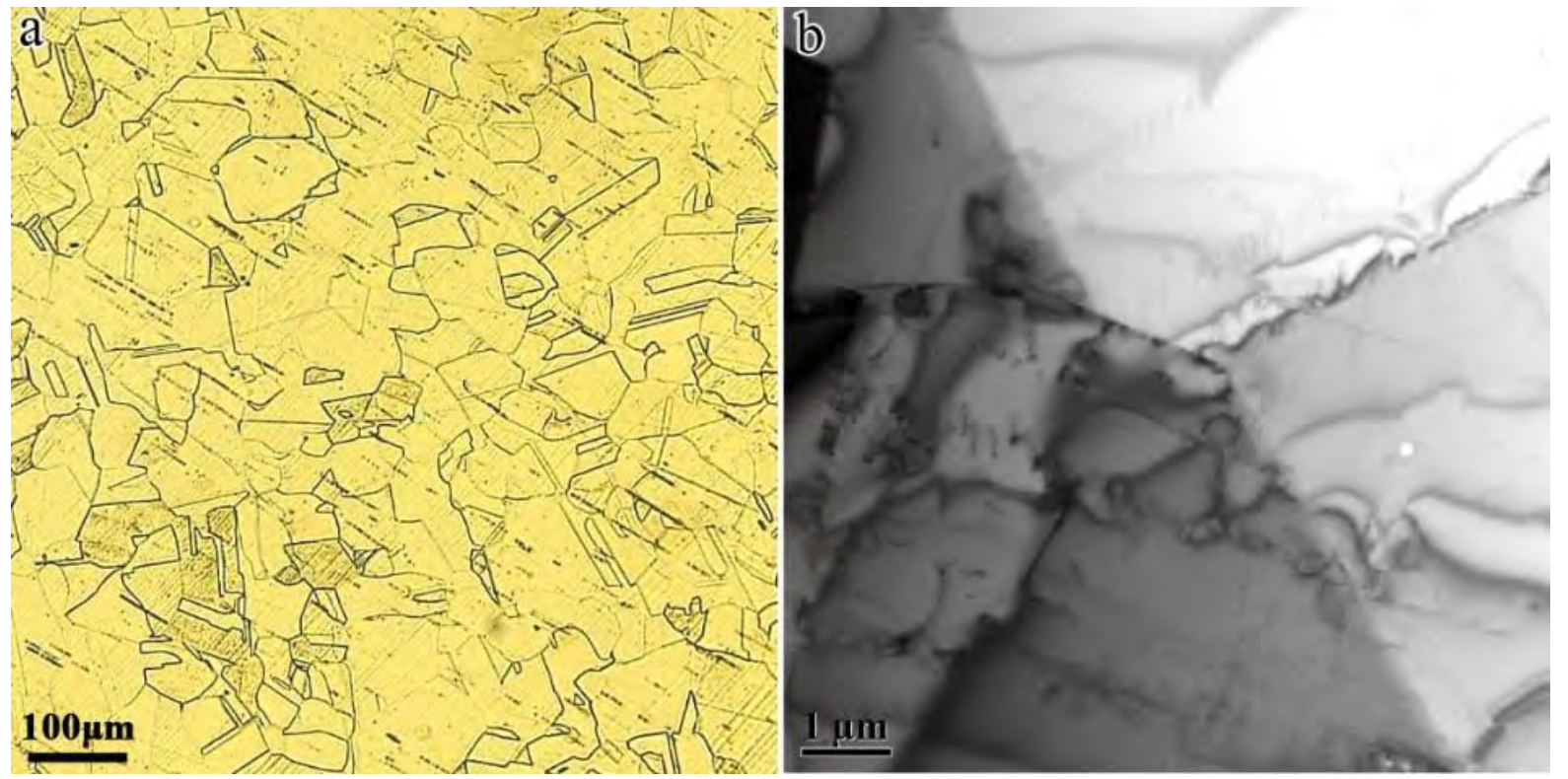

Figure 1. The microstructure of the as-received 316 stainless steel (SS) observed using (a) optical microscopy and (b) TEM. The average grain size is around $60 \mu \mathrm{m}$. Annealing twins are visible in some grains. 


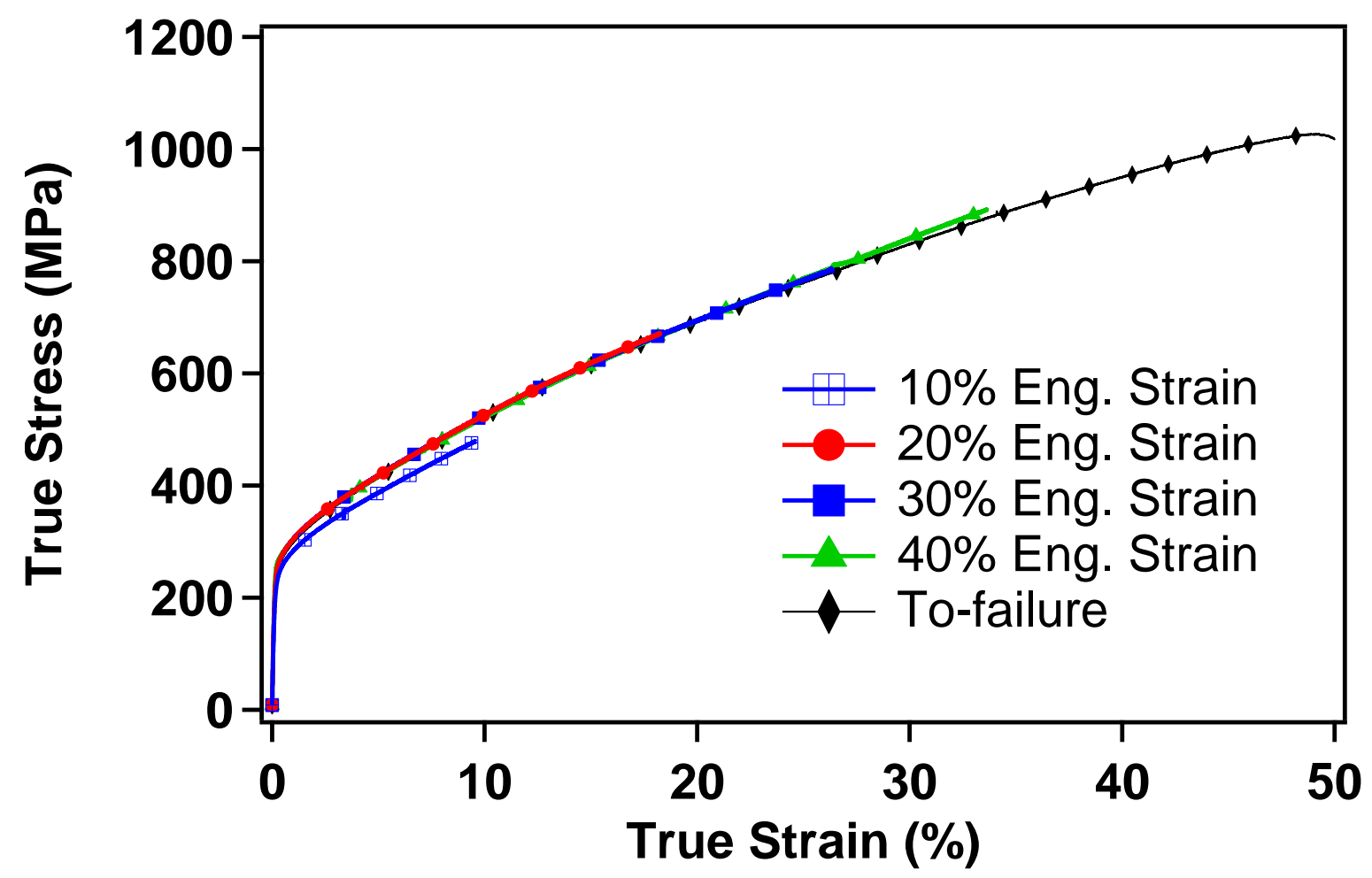

Figure 2. Tensile true stress-strain curves of $316 \mathrm{SS}$ polycrystals, with $10 \%, 20 \%, 30 \%, 40 \%$ applied engineering strains (corresponding to $9 \%, 18 \%, 26 \%$, and $33 \%$ true strain, respectively), and up-to-failure elongation. 

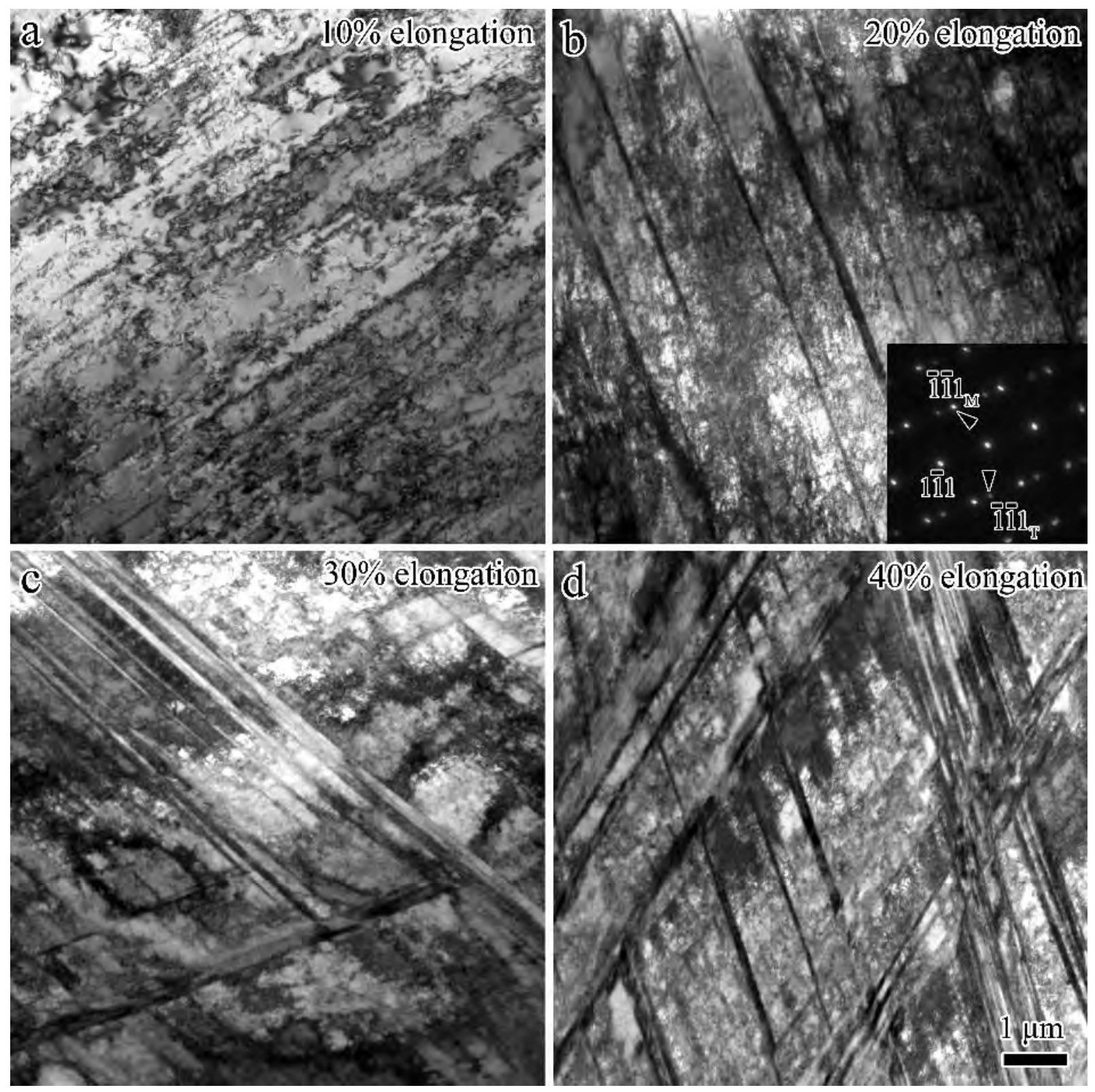

Figure 3. Bright field TEM images of the microstructures after (a) $10 \%$, (b) $20 \%$, (c) $30 \%$ and (d) $40 \%$ tensile elongations. In the $10 \%$ deformed samples, there are numerous planar dislocations. The inserted SADP in (b) shows the observed deformation bands in $(b, c, d)$ to be $\{111\}<112>$ twin bands. The density of the twin bands increases with increasing strain level. 

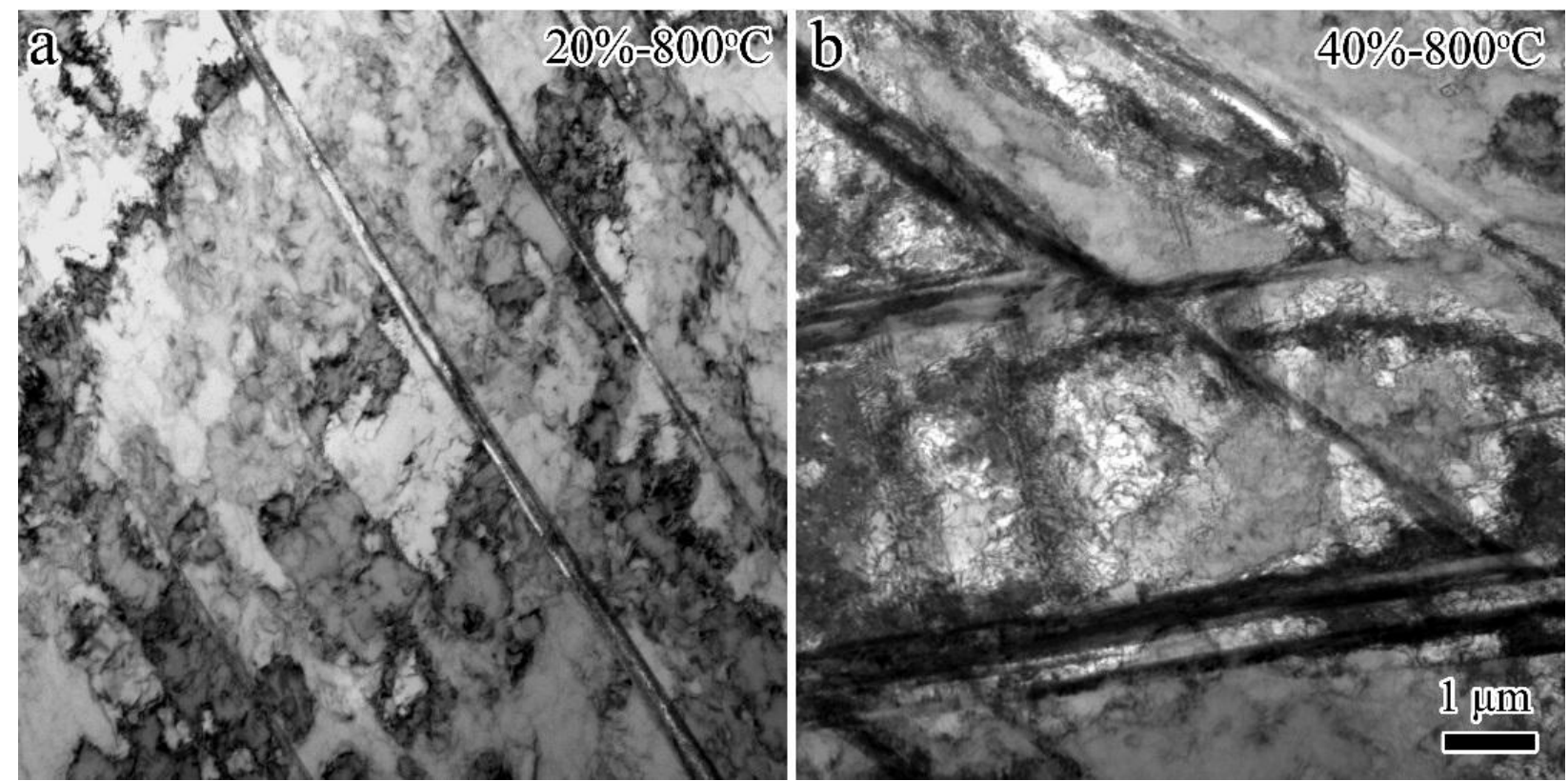

Figure 4. Bright field TEM images of the microstructures of the 316 SS specimens deformed under tension for (a) $20 \%$ and (b) $40 \%$ after annealing at $800^{\circ} \mathrm{C}$ for 1 hour. Many deformation nano-twins survived after the annealing at $800^{\circ} \mathrm{C}$ for 1 hour. Dislocation density decreased notably. 

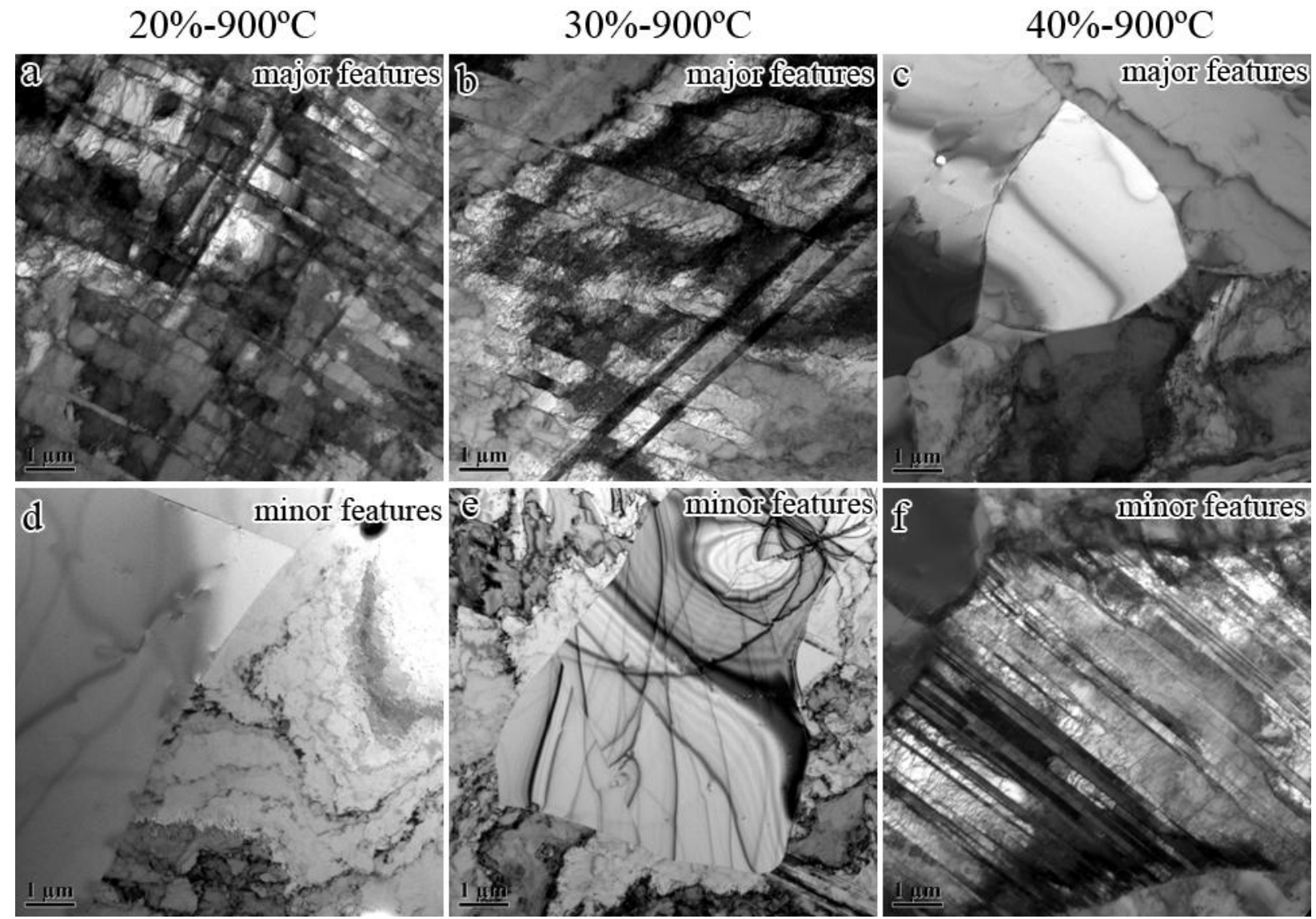

Figure 5. Bright field TEM images of 316 SS showing the major (a-c) and minor (d-f) microstructural features after $900^{\circ} \mathrm{C}$ annealing for 1 hour of the samples deformed under tension at different strain levels (a,d) $20 \%$, (b,e) $30 \%$ and (c,f) $40 \%$. Recrystallization occurs at $900^{\circ} \mathrm{C}$. The major microstructural features remain to be nano-twins in the $20 \%$ or $30 \%$ deformed samples, while the major part of the samples is recrystallized in the $40 \%$ deformed specimens after $900^{\circ} \mathrm{C}$ heat treatment. 


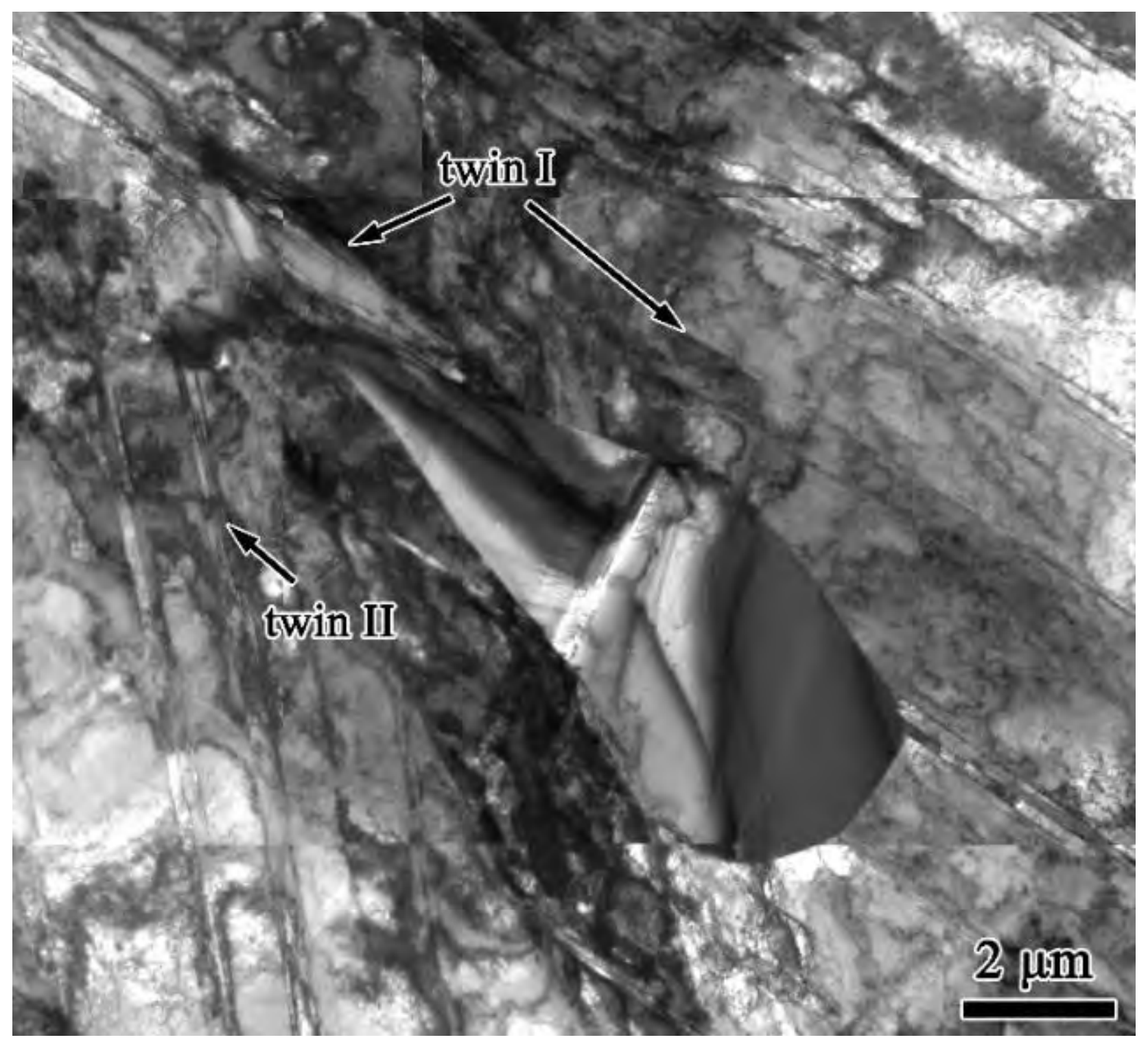

Figure 6. Bright field TEM image collage of the 316 SS specimen deformed to $30 \%$ tensile strain and annealed at $900^{\circ} \mathrm{C}$ for $1 \mathrm{hr}$. The recrystallization starts from the intersection of two different twin variants. 

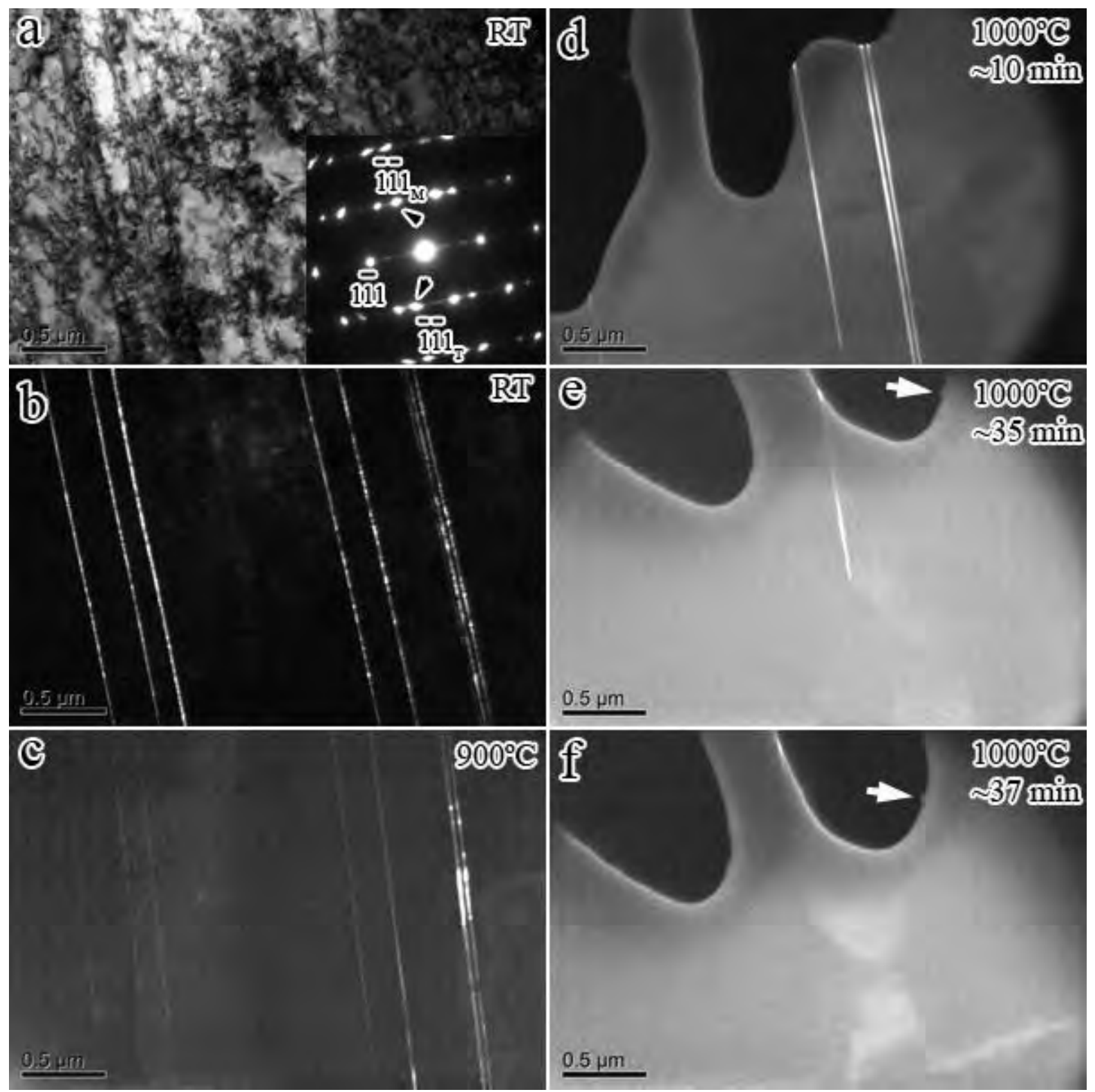

Figure 7. Microstructure evolution under in-situ TEM HT on the $20 \%$ deformed sample of 316 SS. (a, b) Bright and dark field images at RT, respectively; (c) dark field images after heating up to $900{ }^{\circ} \mathrm{C}$, heating up to $1000{ }^{\circ} \mathrm{C}$ and holding temperature for (d) $\sim 10$ minutes, (e) $\sim 35$ minutes and (f) $\sim 37$ minutes. 

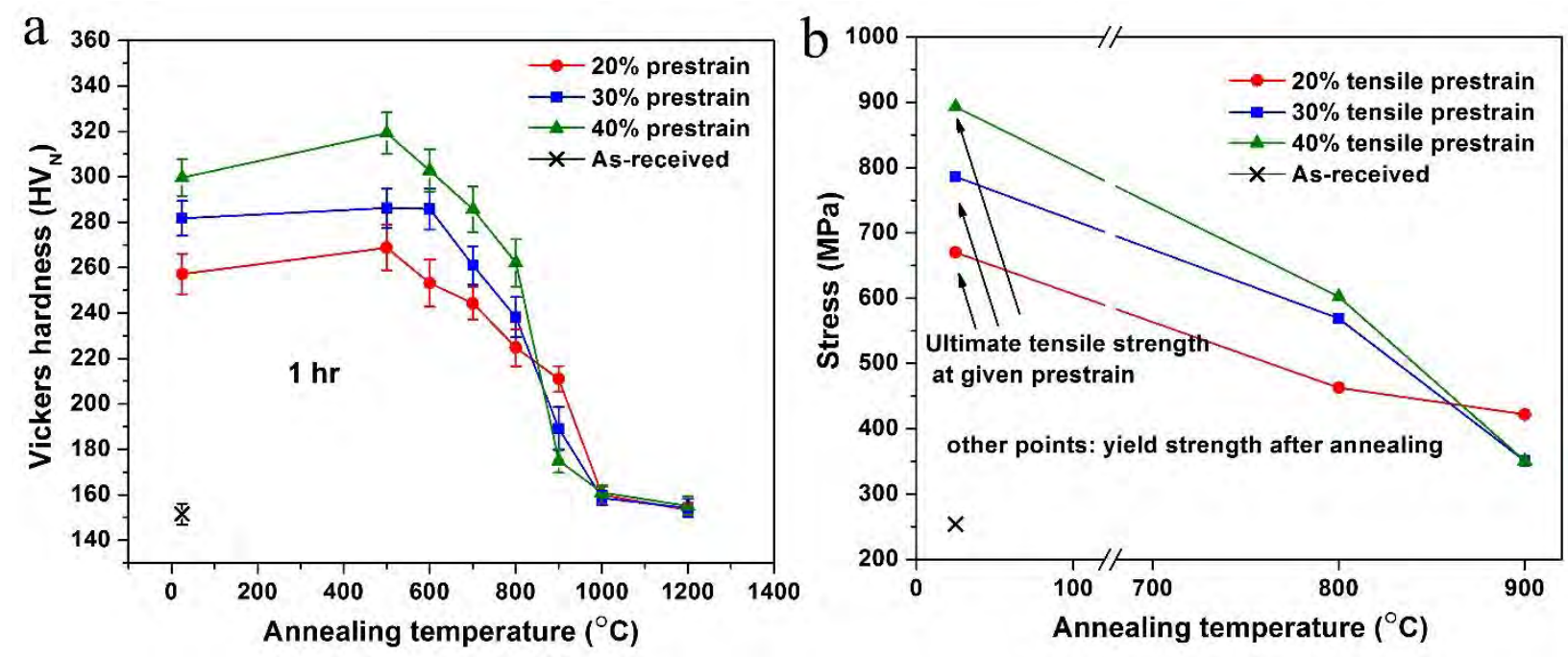

Figure 8. Evolution of Vickers microhardness values (a) and ultimate tensile and yield strengths (b) of various $316 \mathrm{SS}$ samples uniaxially strained to different levels and then, annealed for 1 hour. Softening starts at around $600^{\circ} \mathrm{C}$. The hardness drops significantly after annealing above $800^{\circ} \mathrm{C}$. At $1000^{\circ} \mathrm{C}$, the deformed materials were fully recrystallized and the hardness was comparable to the as-received sample hardness. In (b) the ultimate tensile strength of $20 \%, 30 \%$ and $40 \%$ is included for comparison. 


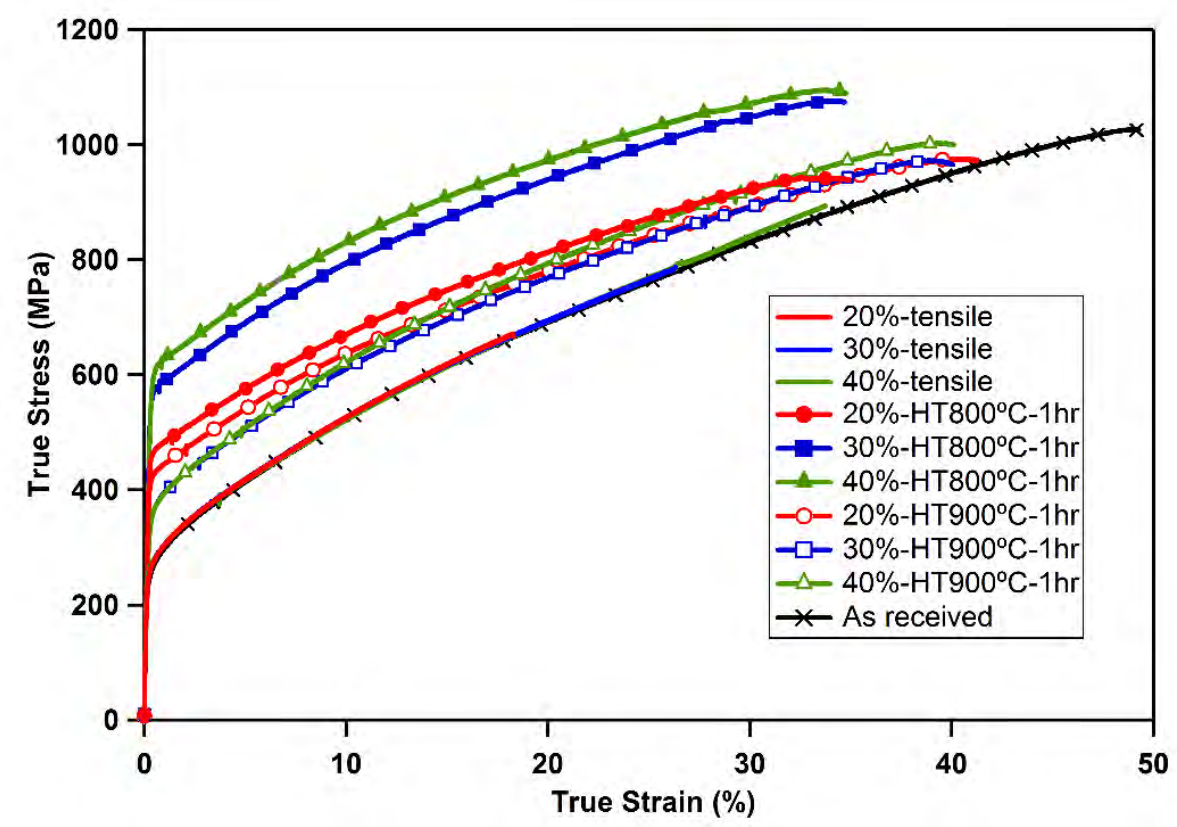

Figure 9. Tensile true stress-strain responses of the as-annealed 316 SS tension samples after various levels of tensile strain. The tensile response of the as-received sample is included for comparison. The marks on the plots were added to distinguish different cases. They do not represent experimental data points.
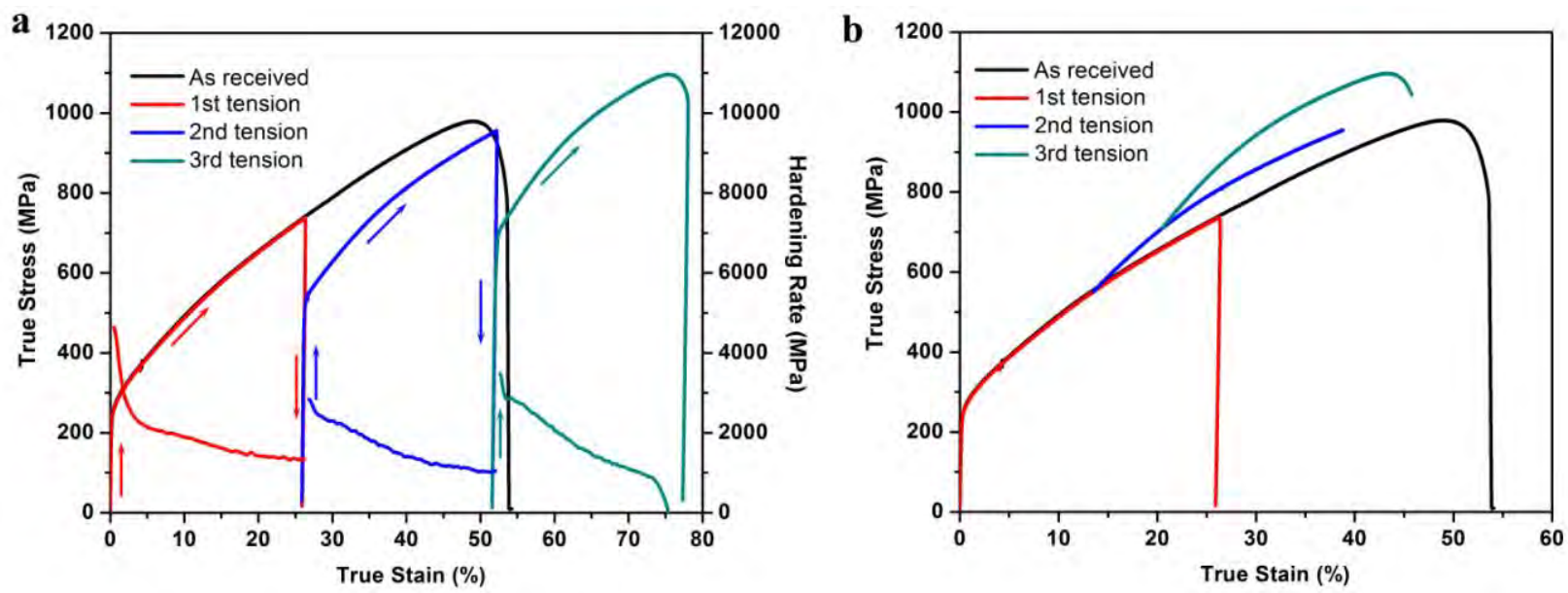

Figure 10. Tensile true stress-strain curves of (a) the 316 SS samples after deformationannealing-deformation cycles. (b) The 2nd and 3rd tension curves were shifted in order to clearly show the strengthening effect of the anneal-tension cycles samples comparing to the as-received sample. Please see text for details. 


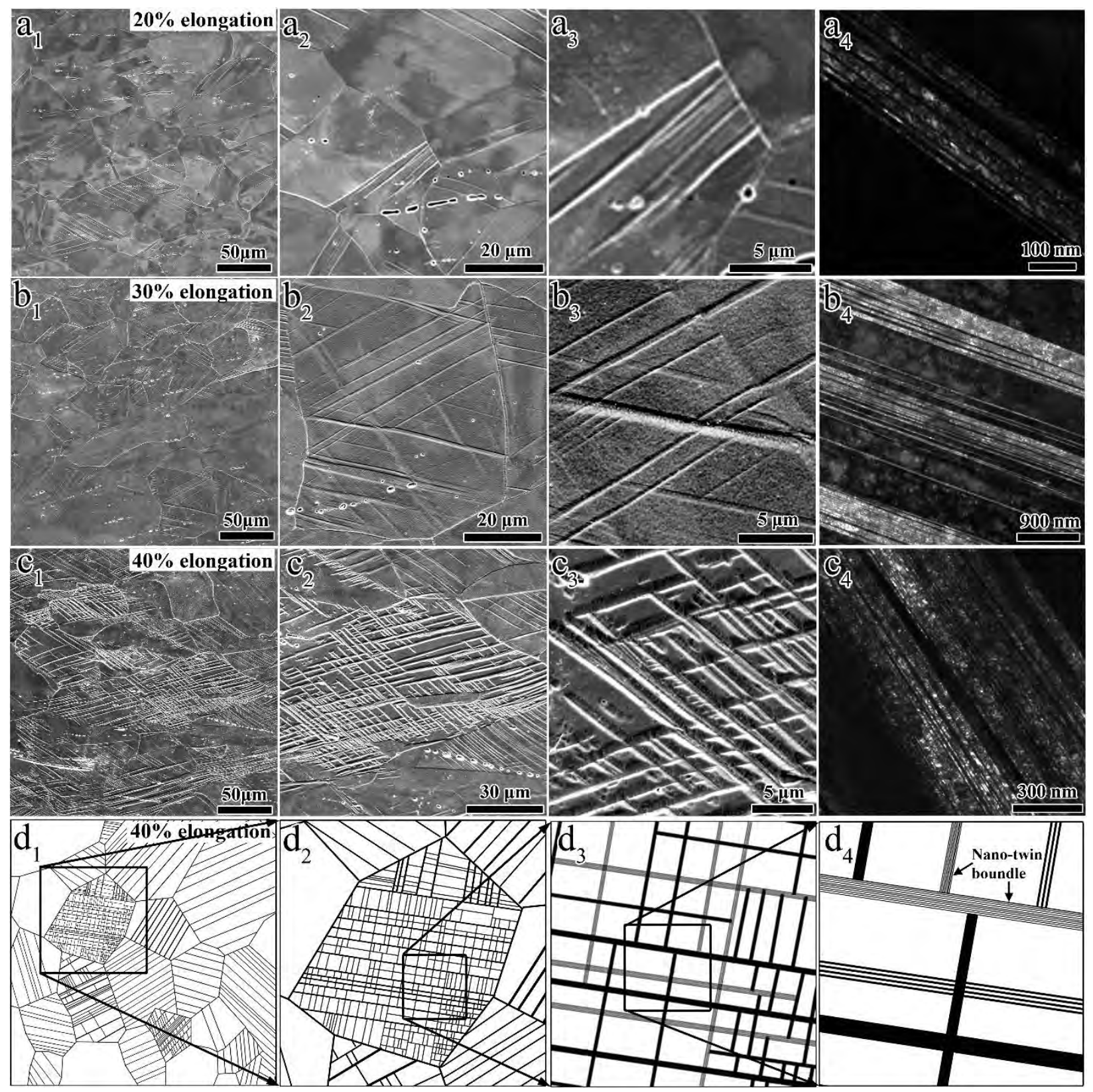

Figure 11. Hierarchical microstructure evolution of $316 \mathrm{SS}$ under a uniform elongation of $\left(\mathrm{a}_{1}-\mathrm{a}_{4}\right)$ $20 \%,\left(b_{1}-b_{4}\right) \quad 30 \%$ and $\left(c_{1}-c_{4}\right) \quad 40 \% .\left(d_{1}-d_{4}\right)$ are the schematic representation of these microstructures for the $40 \%$ deformed case. The volume fraction of the twinned grains increased with increasing strain level. The volume fractions of twins in individual grains increase correspondingly as well. 


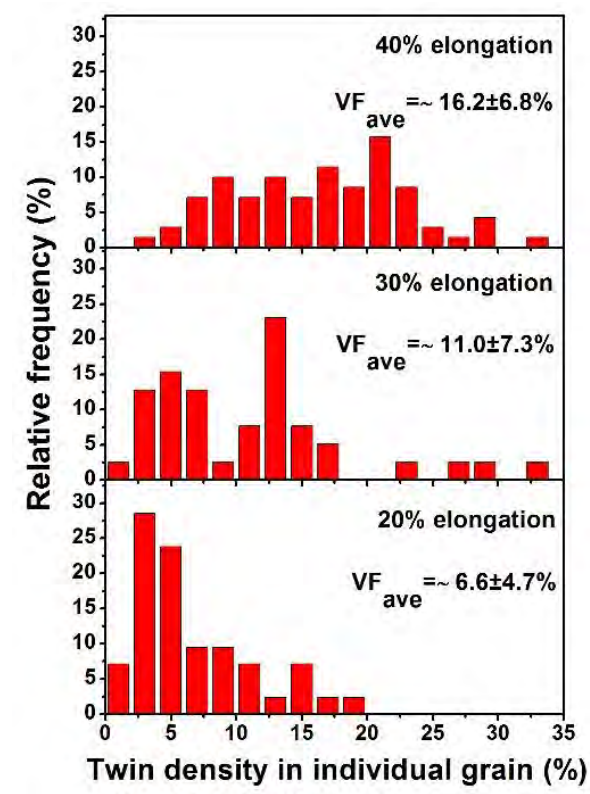

Figure 12. Distribution of twin density within individual grains after tensile deformation to different levels. The average density of twins increases from $\sim 6.6 \% \pm 4.7 \%$ to $\sim 16.2 \% \pm 6.8 \%$ with increasing strain levels from $20 \%$ to $40 \%$, determined from about 70 grains. The maximum twin density in an individual grain was estimated to be around $\sim 33 \%$, which points out the upper limit for the twin density that can be achieved via uniaxial tension deformation. 


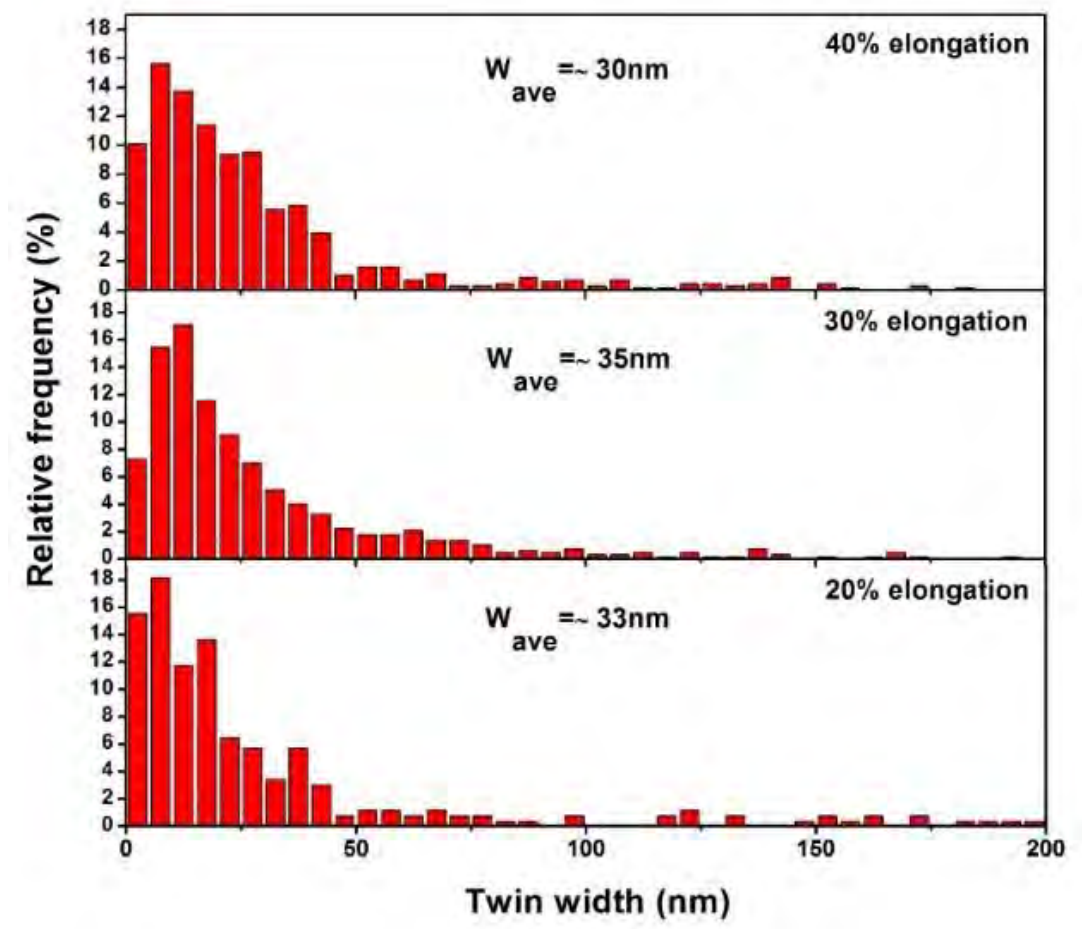

Figure 13. Distribution of the twin width in the tensile deformed 316 SS. Compared to the twin density, the change of twin size with increasing uniaxial strain level was insignificant. More than $\sim 700$ twin bands were counted at their edge-on condition in dark filed TEM images. 


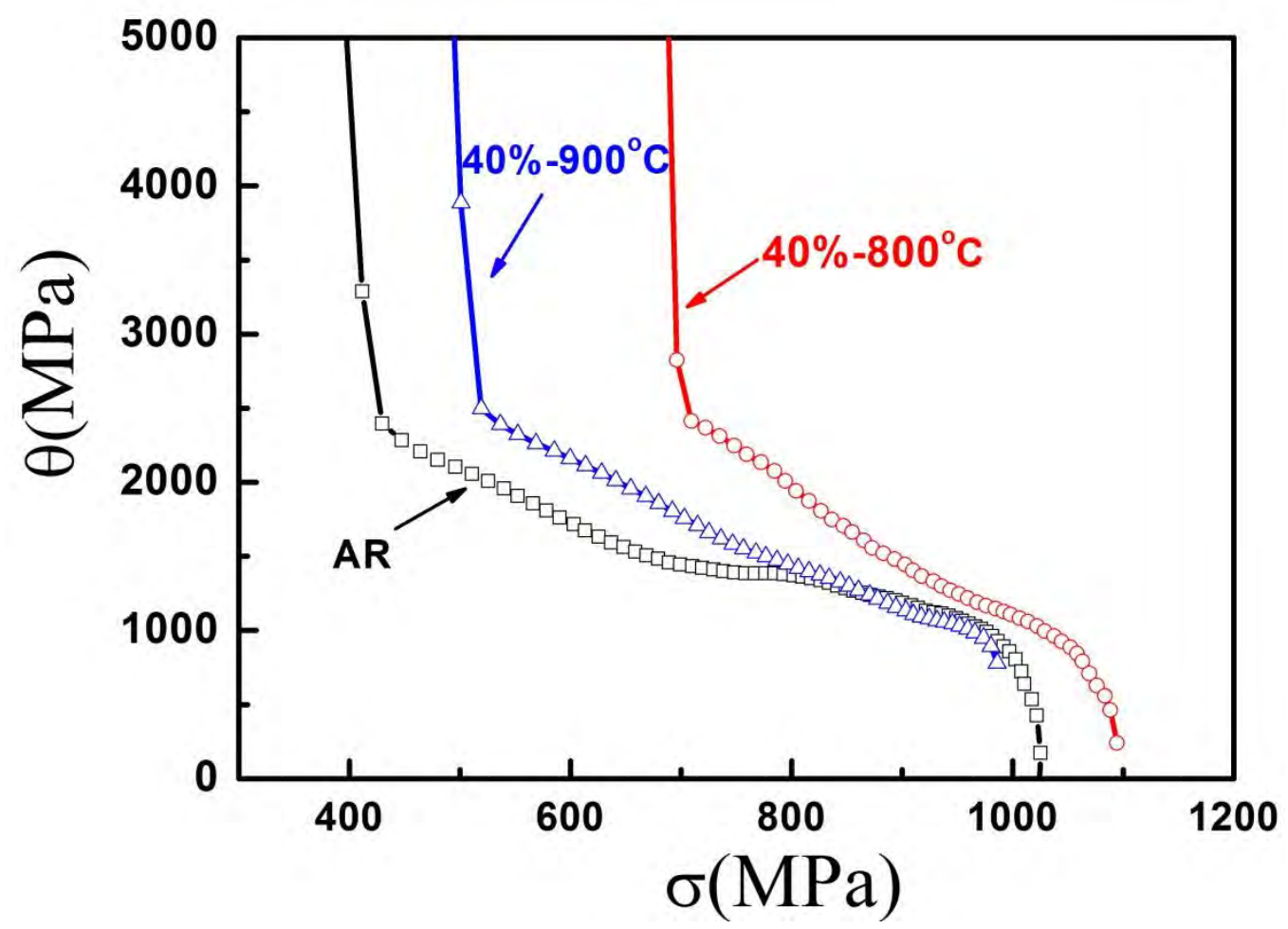

Figure 14. Work-hardening rate $(\theta)$ vs. true stress $(\sigma)$ for the as-received, $40 \%$ tensile deformed and $800^{\circ} \mathrm{C}$ annealed and $40 \%$ tensile deformed and $900^{\circ} \mathrm{C}$ annealed $316 \mathrm{SS}$ samples. The annealing heat treatments were conducted for 1 hour. 


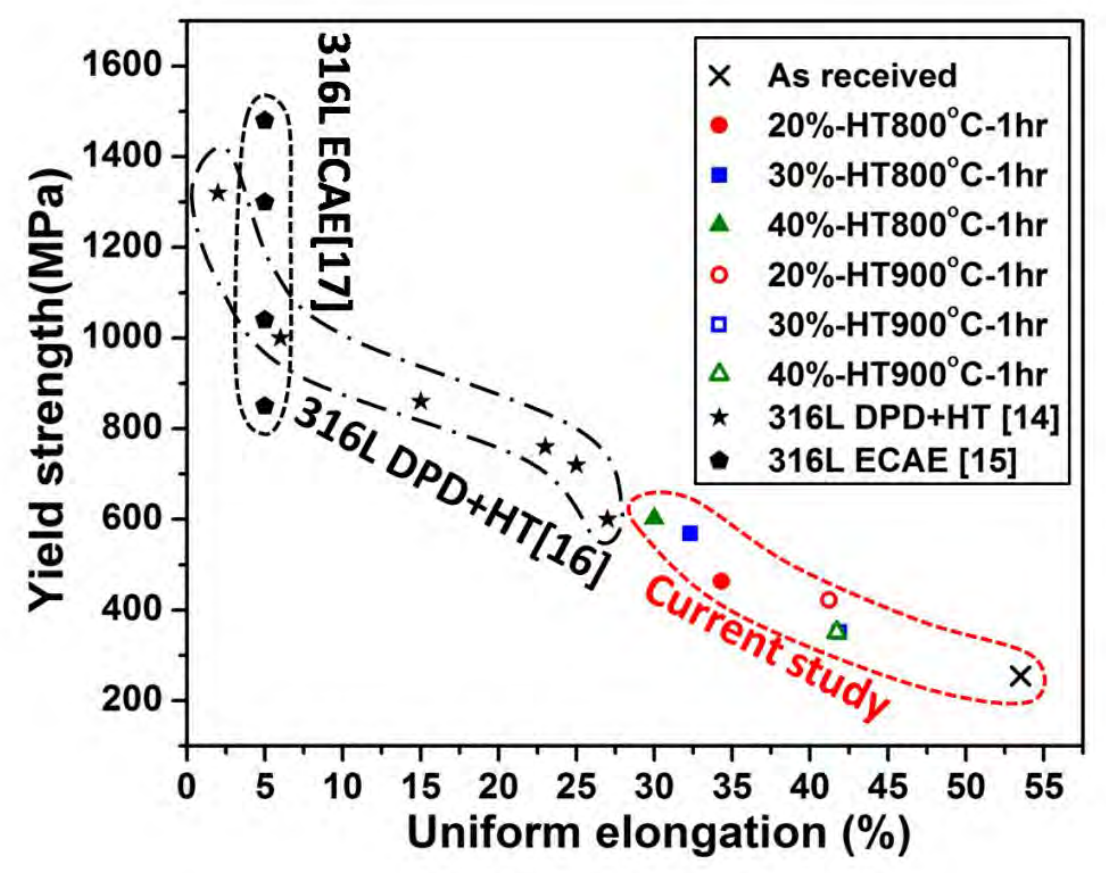

Figure 15. The correlation of yield strength and elongation to failure for the as-received, 20\%$800 / 900^{\circ} \mathrm{C}, 30 \%-800 / 900^{\circ} \mathrm{C}$ and $40 \%-800 / 900^{\circ} \mathrm{C}$ samples of $316 \mathrm{SS}$ samples of the present study. Some literature data for 316L SS $[16,17]$ are included for comparison. 
Table 1. The measured deformation twin densities as a function of applied strain for $316 \mathrm{SS}$ samples deformed under tension to different strain levels.

\begin{tabular}{|c|c|c|c|}
\hline & $\begin{array}{c}\text { Number Density of } \\
\text { Twinned Grains }(\%, \\
\text { from } \sim 500 \text { grains })\end{array}$ & $\begin{array}{c}\text { Twin Volume Fraction in } \\
\text { each Twinned Grain }(\%, \\
\text { from } \sim 70 \text { Grains) }\end{array}$ & $\begin{array}{c}\text { Twin volume fraction in } \\
\text { the Entire Sample }(\%, \\
\text { from } \sim 500 \text { grains })\end{array}$ \\
\hline $20 \%$ & $62.6 \pm 4.6$ & $6.6 \pm 4.7$ & $5.8 \pm 1.5$ \\
\hline $30 \%$ & $77.3 \pm 3.1$ & $11.0 \pm 7.3$ & $9.4 \pm 1.6$ \\
\hline $40 \%$ & $79.5 \pm 4.3$ & $16.2 \pm 6.8$ & $12.5 \pm 2.0$ \\
\hline $30 \%$ cycles & $\sim 100 \%$ & $27.0 \pm 6.6$ & $28.4 \pm 4.5$ \\
\hline
\end{tabular}

